\title{
World Journal of Laparoscopic iliopubic tract repair for pediatric inguinal hernia has very low recurrence: an Indian experience
}

Sunil Kumar Nayak (D), Ramakrishnan Parthasarathi, Raghavendra Gupta G H V, Subbaiah Rajapandian, Nalankilli Vaiyapurigoundar Palanisamy, Chinnusamy Palanivelu

To cite: Nayak SK,

Parthasarathi R, G HV RG, et al. Laparoscopic iliopubic tract repair for pediatric inguinal hernia has very low recurrence: an Indian experience. World Jnl Ped Surgery 2020;3:e000150. doi:10.1136/ wjps-2020-000150

Received 19 May 2020 Revised 25 July 2020 Accepted 30 July 2020
Check for updates

\section{(c) Author(s) (or their} employer(s)) 2020. Re-use permitted under CC BY-NC. No commercial re-use. See rights and permissions. Published by BMJ.

Minimal Access Surgery, GEM Hospital and Research Centre, Coimbatore, Tamil Nadu, India

Correspondence to Dr Sunil Kumar Nayak; nayaksunil0203@gmail.com

\section{ABSTRACT}

Background The aim of this study is to document results of laparoscopic iliopubic tract (IPT) repair for inguinal hernia in the pediatric age group.

Methods Hospital records of 190 children who underwent IPT repair between January 2015 and January 2020 were analyzed retrospectively for demographic details, variations between clinical, radiological and laparoscopic diagnosis, associated pathologies, operative time, hospital stay, postoperative complications and follow-up. The internal ring was narrowed by approximating IPT to conjoint tendon using 3-0 polypropylene continuous or interrupted suture.

Results In total, 238 IPT repairs were done under general anesthesia in 190 children aged between 1 and 17 years. $7.9 \%$ of children had phimosis, and three children had hydrocele. Three patients had undescended testis and another three IPT repairs were done in cases who presented with appendicitis. Contralateral patent processus vaginalis (CPPV) was detected at the time of laparoscopy in $18.3 \%$ of cases. Thus far, 166 children had been followed, and no recurrence was observed in any of these 96 of whom have completed more than 3 years after their surgery. However, two patients developed hernia on the contralateral side.

Conclusions Laparoscopy is beneficial to pick up CPPV. Laparoscopic IPT repair for pediatric inguinal hernia is reproducible and safe with the least recurrence reported thus far. However, further follow-up is needed. Moreover, development of contralateral hernia needs to be investigated.

\section{INTRODUCTION}

Inguinal hernia repair is one of the most common surgeries performed in the pediatric age group with a reported incidence of $0.8 \%-4.4 \%{ }^{1}$ Failed closure of the processus vaginalis has been the most commonly cited reason for pediatric inguinal hernia. However, despite being a prerequisite, it is not the only factor responsible and other factors are involved. Usually the defect has been present since birth to a variable extent; however, patients may present at birth as well as later ranging from days to years. Diagnosis is mostly clinical based on history and physical

\section{Summary box}

What is already known about this subject?

- Inguinal hernia is a common condition in pediatric age group.

- Multiple techniques from open to laparoscopic methods of its management are available.

- Laparoscopic repair comes with certain advantages but has slightly higher recurrence compared with open.

- Every effort should be made to reduce recurrence to an absolute minimum.

What are the new findings?

- Laparoscopic iliopubic tract (IPT) repair has the least recurrence reported thus far for pediatric inguinal hernia.

- It is safe and reproducible along with the advantage of simultaneous exploration of the other side.

- It should be employed for inguinal hernias in older children or with wide deep ring.

\section{How might it impact clinical practice in the}

\section{foreseeable future?}

- IPT repair is a less commonly used technique but has excellent results and hence needs a wider application in well-selected patients.

examination, but few cases will need investigations, such as ultrasonography (USG). Surgery is recommended expeditiously with few exceptions, and an open approach has given excellent results. ${ }^{1}$

That said, challenges do exist with the open approach, such as postoperative hydrocele, trauma of access, damage to cord structures due to handling, and most importantly exploration of contralateral groin. Laparoscopy has been introduced with the aim of overcoming these shortcomings and has been used for pediatric inguinal hernias for some time. Multiple intracorporeal and extracorporeal techniques of laparoscopic repair have been described. We performed our first laparoscopic iliopubic tract repair (LIPTR) in 
1994. We believe that a routine laparoscopic ring closure (LRC) is insufficient for children with a wide internal ring (we consider an internal ring to be wide if its diameter is more than twice that of the cord structures). We also observed two recurrences 5 months after LRC and none after LIPTR. ${ }^{2}$ Since then, we have been preferably using LIPTR in children more than 2 years of age or in those with wide ring. Our results of LRC and LIPTR were published in $2005 .{ }^{2}$ In the following sections, we discuss the benefits of laparoscopic surgery in pediatric inguinal hernia, and we present an analysis of our data on laparoscopic IPT (iliopubic tract) repair for 238 inguinal hernias from January 2015 to January 2020.

\section{METHODS}

\section{Study design}

This retrospective, single-center study was conducted at a tertiary care referral center in India for hernia and GI surgery from January 2015 to January 2020. All children ( $\leq 18$ years) who underwent LIPTR were included for analysis. Children who underwent other techniques of hernia repair, such as LRC, were excluded from the study. Our hospital database was searched, and a total of 238 LIPTRs in 190 children were selected for analysis in terms of demographic features, variations between clinical, radiological and laparoscopic diagnosis, associated pathologies, operative time, hospital stay, postoperative complications and follow-up.

All children were admitted in the evening prior to surgery and were discharged on postoperative day 1 as per hospital policy in the absence of any complications. Surgical work-up consisted of basic blood investigations and ultrasonography.

\section{Laparoscopic IPT repair: surgical procedure}

Patient is in supine position under general anesthesia with monitor at the foot-end side. Surgeon stands on the head end with camera surgeon to his left. In supine position, incision is made at the lower edge of umbilicus. $\mathrm{CO}_{2}$ pneumoperitoneum is created with pediatric Veress needle in all cases with intra-abdominal pressure set at $10 \mathrm{~mm}$ of mercury. A $5 \mathrm{~mm}$ scope is used for camera at the umbilicus. Thereafter, two $3 \mathrm{~mm}$ ports are placed through the left and right pararectal region maintaining triangulation (figure 1). The first step involves a thorough inspection of the abdomen along with both the inguinal regions (figure 2A,B). Then the peritoneum is incised lateral to the internal ring, at the neck of the sac (figure 3A). Incision is extended along the superior aspect of the ring (figure 3B), sac is identified, dissected completely from cord structures (figure 3C) and divided (figure 3D). All dissection is done under vision without handling the vas or testicular vessels. Thereafter, on needle 3-0 polypropylene is introduced lateral to the internal ring by directly piercing the abdominal wall (figure 4A). Because the abdominal wall is thin in the pediatric age group,

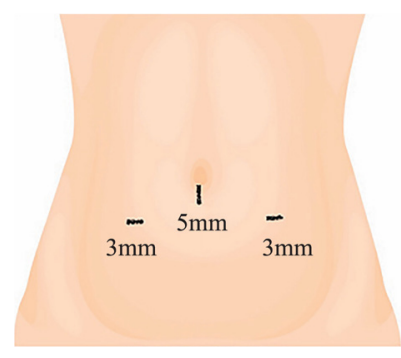

Figure 1 Port sites used for laparoscopic bilateral iliopubic tract repair. In case of unilateral defect, the opposite port is made little lower.

there is no problem in taking the needle in. The tail end is left out for manipulation, and this also ensures a short length of thread is inside for easy suturing. IPT is a white shining band that runs underneath the cord structures at the inferior aspect of the internal ring, and the conjoint tendon lies above and lateral to the ring. The IPT is approximated without tension to the conjoint tendon using non-absorbable 3-0 continuous suture, hence narrowing the internal ring (figure 4B,C). Thereafter, we suture back laterally, and we cut the suture externally near the abdominal wall and pull the tail end in to ensure a short length of suture inside. Then we tie the knot at the starting point of suturing (figure 4D). Too tight approximation must be avoided. Also, during the repair, care should be taken not to handle the cord structures. The peritoneum is then closed with 4-0 absorbable sutures (figure 5A-D). Trocar entry sites are sealed with cyanoacrylate glue.

Liquids are started when the child is well alert, and solids are started after 8 hours. Patients can be discharged during evening of the day of surgery; however, we routinely discharge patients on postoperative day 1 . All patients in this series were assessed after 1 week and 4 weeks at hospital. Thereafter, patients were telephoned annually to assure their medical health. Consultation was advised if any problem was suspected.

\section{RESULTS}

A total of 238 IPT repairs (for 142 unilateral and 48 bilateral defects) were performed on 190 patients (135 boys and 55 girls). The mean age was $8.78 \pm 3.82$ years.
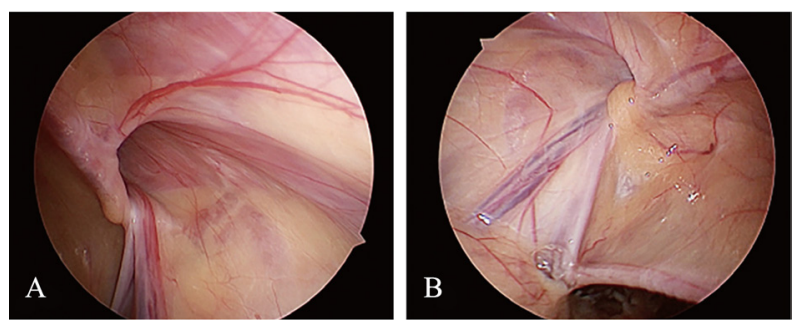

Figure 2 Laparoscopic view of right (A) and left (B) inguinal rings in a patient with bilateral inguinal hernia. 

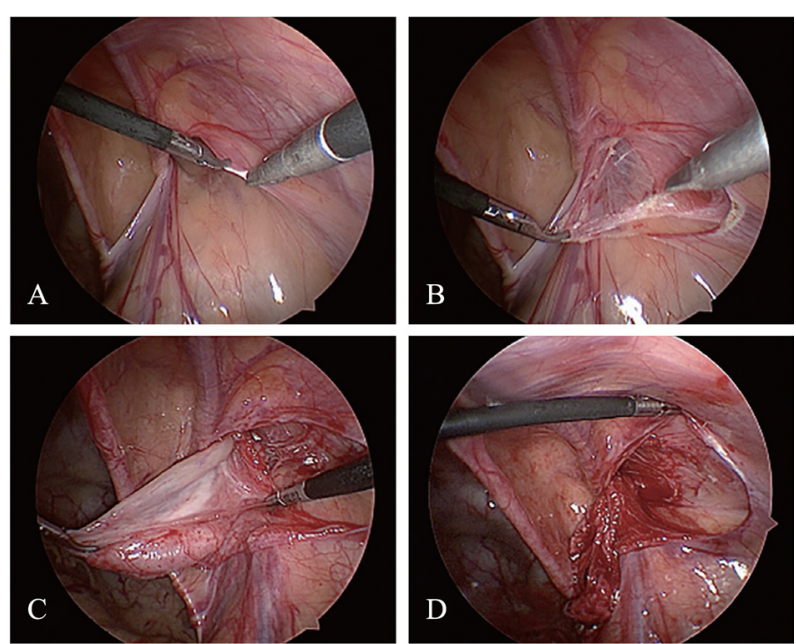

Figure 3 Peritoneum is being incised lateral to the internal ring, at the neck of the sac (A). Incision is extended along the superior aspect (B), sac is dissected completely $(C)$ and divided (D).

The average duration of surgery was $36.4 \pm 5.4$ minutes for unilateral cases and 51.2 \pm 7.6 minutes for bilateral cases. All the cases were performed under GA. Patients were allowed orally as soon as they were alert. No significant complications were observed during the immediate postoperative period, and mean postoperative hospital stay was 1 day.

Preoperatively, bilateral hernia was diagnosed clinically in 17 cases. USG revealed bilateral hernia in additional four cases. Intraoperatively on laparoscopy, 31 (18.3\%) patients had contralateral patent processus vaginalis (CPPV). Preoperative diagnosis in this subgroup was LIH (left inguinal hernia) in 11 cases and RIH (right inguinal hernia) in 20 cases. In this series, a total of 52 patients had bilateral defects. Four of them had small defects
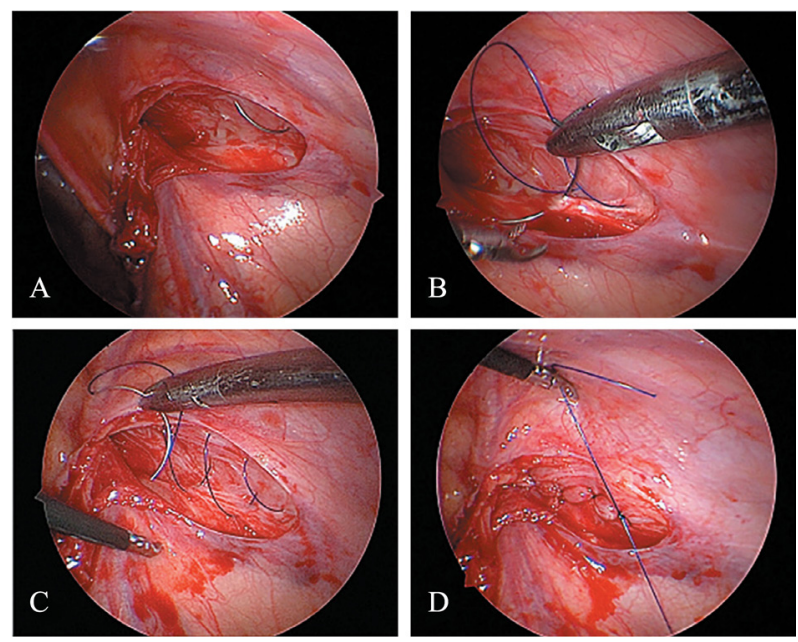

Figure 4 Needle is being introduced lateral to the internal ring $(A)$. The iliopubic tract is approximated to the conjoint tendon from lateral to medial aspect $(B, C)$. Thereafter, sutures are taken in reverse manner to tie the knot at starting point (D).
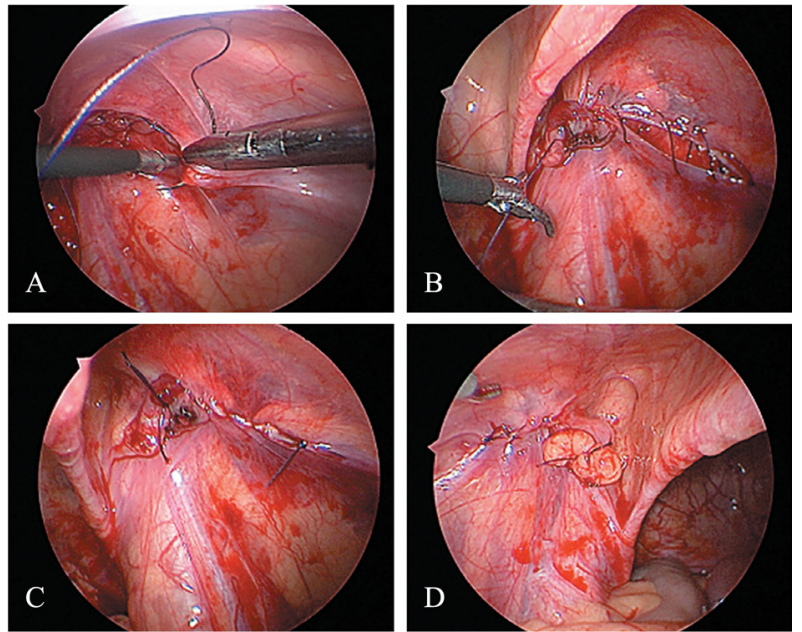

Figure 5 Peritoneum is being closed from lateral to medial aspect on the right side $(A-C)$. Laparoscopic view of the left side after peritoneal closure (D).

on the other side and underwent ring closure for same. These results are summarized in table 1 .

Fifteen $(7.9 \%)$ patients had phimosis and underwent circumcision simultaneously. Three had hydrocele, and three patients had undescended testis. Three $(1.6 \%)$ patients had appendicitis, and appendicectomy was completed along with IPT repair.

Three patients were operated for recurrent hernias. One patient underwent laparoscopic bilateral IPT repair 5 years earlier and had recurrent hernia on both sides. Another two patients underwent surgery for recurrence post right herniotomy.

In the immediate postoperative follow-up, 11 patients complained of mild pain in the groin region/umbilicus but responded to conservative measures. No other

Table 1 Results highlighting demography, preoperative and intraoperative factors

\begin{tabular}{ll}
\hline Variable & Observed value \\
\hline Total IPT repairs & 238 \\
\hline Total patients, $\mathrm{n}$ & 190 \\
\hline Male/female, $\mathrm{n}$ & $135 / 55$ \\
\hline Mean age (year) & $8.78 \pm 3.82(2-17)$ \\
\hline Right:left:bilateral defect, $\mathrm{n}$ & $87: 51: 52$ \\
\hline Average duration of surgery & \\
\hline \multicolumn{1}{|c}{ Unilateral cases (min) } & $36.4 \pm 5.4$ \\
\hline \multicolumn{1}{|c}{ Bilateral cases (min) } & $51.2 \pm 7.6$ \\
\hline $\begin{array}{l}\text { Mean postoperative hospital } \\
\text { stay (day) }\end{array}$ & \\
\hline Bilateral cases, $\mathrm{n}(\%)$ & $52(27.4)$ \\
\hline Clinical/radiological, $\mathrm{n}(\%)$ & $21(11)$ \\
\hline CPPV in laparoscopy, $\mathrm{n}(\%)$ & $31(18.3)$ \\
\hline
\end{tabular}

${ }^{*}$ Data are presented with mean $\pm S D$.

CPPV, contralateral patent processus vaginalis; IPT, iliopubic tract; $\mathrm{SD}$, standard deviation. 
complications, including seroma, were noted. Twentyfour patients could not be followed up in long term. The remaining 166 patients were followed up for a mean period of 34 months, with more than 3 years of follow-up for 96 patients. No recurrence was observed in any of the patients in this series. None reported testicular atrophy.

However, two patients developed metachronous contralateral hernia. Also in this series, we operated bilateral inguinal hernia in a patient with a history of laparoscopic appendicectomy 1 year prior. We also did a left IPT repair in a patient who had undergone right IPT repair 10 years ago. Both these patients had normal internal rings at the time of their previous surgery.

\section{DISCUSSION}

Laparoscopic pediatric inguinal hernia repair was first described for girls in 1997 by El-Gohary. The authors inverted the hernia sac into the peritoneal cavity and placed an endoloop at the base in 28 females. ${ }^{3}$ However, owing to non-exclusion of cord structures, this procedure could not be applied in boys. In 1998, Schier reported closure of the processus vaginalis using two to three intracorporeally placed Z-stitches in 14 females. ${ }^{4}$ Montupet and Esposito ${ }^{5}$ were the first to report the successful use of laparoscopy for inguinal hernia repair in boys. They placed purse string sutures around the neck of the sac excluding cord structures. Schier introduced his technique of the placement of $\mathrm{Z}$ stitch in either sex in $2003 .{ }^{6}$ A total of 279 patients with 403 hernias were included and a recurrence rate of $2.7 \%$ was noted. Becmeur et $a l^{7}$ described resection of the hernia sac following peritoneal division at the level of the internal ring. This was followed by closure of the peritoneal edges. Other techniques, such as W-type suture ${ }^{8}$ and flip flap technique, ${ }^{9}$ have been described. Also, extracorporeal techniques have been described. These involve circumferential suture placement around the internal ring percutaneously and subsequently tying the knot. These include single-port laparoscopically assisted simple suturing obliteration (LASSO) $)^{10}$ with the use of epidural needle for pre-peritoneal hydrodissection, and subcutaneous endoscopically assisted ligation (SEAL). ${ }^{11}$ However, which technique is better is still debated. A recent review article $^{12}$ mentioned that there was insufficient evidence to support one particular approach over the other. However, the technique involving creation of the peritoneal incision at the internal inguinal ring and subsequent closure, as reported by Montupet and Esposito, ${ }^{5}$ seems to result in better repair.

IPT repair is a less reported procedure for management of groin hernias. Grosfeld et $a l^{13}$ reported their experience with open IPT repair in 20 cases of recurrent indirect hernia in 1991. Thereafter, we reported our initial experience of 93 laparoscopic inguinal hernia repairs (71 LRCs and 22 LIPTRs) in $2005 .{ }^{2}$ Owing to the recurrence we observed with laparoscopic ring closure and a higher age of presentation compared with pediatric centers, we have routinely been employing laparoscopic IPT repair in children greater than 2 years of age or in those with a wide internal ring. There is no consensus definition of a wide ring, and our definition is based on experience. A recent article by Shehata et $a l^{14}$ proposed pediatric Nyhus (PN) classification system for a tailored treatment of pediatric inguinal hernias. Along with herniotomy, the authors recommended narrowing of deep ring for PN type II and IPT repair for PN type III hernias. These had a mean deep ring diameter of $16.7 \mathrm{~mm}$ and $22.6 \mathrm{~mm}$, respectively.

Multiple postoperative complications have been reported including scrotal swelling, iatrogenic cryptorchidism, injury to the vas, testicular atrophy, intestinal injury, chronic pain and recurrence. ${ }^{1}$ We did not observe any major early postoperative complication including seroma as we reduced the sac completely/excised the sac as a part of the procedure. We also did not come across any postoperative hematoma, a potential complication due to the greater dissection involved. Further any possibility of iatrogenic cryptorchidism as a result of traction due to distal sac inside the abdomen is reduced by division of the excess sac. We did not come across any such complication. Although no recurrences were observed in the previous and present series, we encountered one recurrence in a patient 5 years post IPT repair. Laparoscopic surgery in pediatric inguinal hernias has been reported to have higher recurrences. The reported recurrence rate for open hernia repair in general is around $0.8 \%$. For premature infants, it is about $15 \%$ and $20 \%$ after operation for incarcerated hernias. ${ }^{1}$ Thus far, we have encountered only one recurrence (not included in the present series) post IPT repair. These results have been reflected in a recent study by Lee and Park ${ }^{15}$ who reported that addition of IPT repair to high ligation significantly reduced recurrence although small.

Laparoscopic inguinal hernia repair has been used fairly commonly in adults. However, owing to small incisions, relatively easy repair compared with adults and the less amount of pain patients experience postoperatively in the open approach, along with rapid return to normal activities, laparoscopy as an alternative to open repair was accepted only a few years ago and with a lot of apprehension. Laparoscopic repair (LR) has also been used for direct ${ }^{16}$ and recurrent ${ }^{17}$ inguinal hernias. A recent meta-analysis ${ }^{18}$ showed that children who underwent LR had greater chance of wound infection but less chance of ascending testis and metachronous hernia compared with children for whom open repair (OR) was performed. There were no significant differences between groups in surgical time, length of hospitalization, intraoperative injury, bleeding, testicular atrophy or hydrocele. In addition, there was less postoperative pain and need of rescue analgesia after surgery in the LR group. Three studies included in this meta-analysis found LR to be superior in overall cosmetic results, whereas two found no significant difference. Three other studies in the analysis described the cosmetic results as very satisfactory. 
In another systematic review and meta-analysis, ${ }^{19}$ no differences in postoperative complication and recurrence were found. Surgical time for unilateral repair, total hospitalization period, and time taken to recover fully were also comparable. Subgroup analysis of laparoscopic approaches (intracorporeal suturing and extracorporeal suturing techniques) was also done. Laparoscopic repair with extracorporeal suturing technique had less complications as well as less unilateral surgical time, whereas with an intracorporeal suturing technique, length of hospital stay was shorter. However, clinical relevance of the last two findings is negligible. We conduct a preoperative USG in all patients to confirm our clinical findings, to check the contralateral side and to rule out other abdominal pathologies before proceeding on to surgery. USG is a dependable tool for diagnosing hernias when proper measurements are used, and a good history is present. ${ }^{20}{ }^{21}$ USG also has the potential utility to evaluate the contralateral groin in patients with unilateral hernias.

The ability to identify CPPV is one major advantage of laparoscopy with a reported rate of $23 \%-39 \% .{ }^{22}{ }^{23}$ In our series, this rate was $18.3 \%$, slightly lower possibly due to comparatively older age in our series and also the use of preoperative USG. At birth, almost 80\%-100\% infants have patent processus vaginalis. Closure, if it occurs, then mostly happens within the first 6 months of life. After 6 months of age, patency rates fall more gradually and plateaus around age 3 to $5 .{ }^{1}$ We repaired all contralateral patent inguinal rings as children in our series were older in age and as there are very less chances of their spontaneous closure. If not repaired, this would leave behind a potential opening for hernia development in future.

In addition, there are greater chances of a patent contralateral ring if the initial diagnosis is a left-sided hernia, as has been shown in a literature review that the processus vaginalis closes earlier on the left side than on the right side. ${ }^{24}$ This assumption was not correct for our study because we had more contralateral patent defect when the initial diagnosis was a right inguinal hernia compared with left (20 vs 11).

Certain other conditions requiring surgical intervention were present simultaneously. Among these, phimosis was the most common $(7.9 \%)$ in our series while undescended testis was present in only three patients $(1.6 \%)$. Notably, we found appendicitis in three patients $(1.6 \%)$ which may be the reason that hernia was noticed. All three patients had a right-sided hernia.

Occurrence of metachronous contralateral hernia $(\mathrm{MCH})$ has been described at a rate of $5.8 \%-11.6 \%$ after unilateral hernia repair. ${ }^{25}{ }^{26}$ However, these reports are post open inguinal hernia surgery. Post laparoscopy, the incidence of $\mathrm{MCH}$ is at $0.9 \%$, similar to that in our series. This is even after ruling out a patent ring at laparoscopy, which signifies an ongoing process and the need to further evaluate the development of hernia.

The average duration of surgery in our series was slightly higher (36.4 minutes for unilateral cases and 51.2 minutes for bilateral cases) compared with that reported for open surgery and other laparoscopic surgery series.

This study has certain limitations. It is a retrospective study and has a wide age range. Also, the definition of wide internal ring needs to be refined further and should be based on consensus. Additional follow-up is needed to accurately predict the long-term complications. We have not been able to find the reason for development of metachronous hernia after a normal initial laparoscopy. The technique described is relatively difficult compared with other simpler laparoscopic procedures and may need a greater learning curve, which has not been defined in the present study.

In conclusion, laparoscopic IPT repair is reproducible, safe and an excellent technique for inguinal hernia management in pediatric age group, especially in older children and in those with a dilated ring. It has the least recurrence rate among all reported surgical techniques for pediatric inguinal hernias along with all the benefits of laparoscopy (ie, vas and gonadal vessels are under vision, other hernias (femoral/ direct) are not missed, and other pathologies like appendicitis can be managed simultaneously along with overall better cosmesis and recovery). In addition, by laparoscopy, CPPV can be identified and managed. Further follow-up is needed and development of contralateral hernia needs to be investigated more.

\section{Twitter Sunil Kumar Nayak @sunilnayak21}

Contributors SKN and RP contributed to the planning, data collection, analysis and manuscript preparation of the study. RGGHV, NVP and SR participated in the revision of the manuscript and approval of the final version. CP was involved in the planning of this work, approved the final version and takes the responsibility for the overall content as guarantor. The corresponding author attests that all listed authors meet authorship criteria and that no others meeting the criteria have been omitted.

Funding The authors have not declared a specific grant for this research from any funding agency in the public, commercial or not-for-profit sectors.

Competing interests None declared.

Patient consent for publication Not required.

Ethics approval GEM Hospital ethics committee has approved this study. The ethical committee has approved a waiver of consent given the retrospective nature of the study involving evaluation of maintained data. All efforts were made to keep the individual patient's identity anonymous.

Provenance and peer review Not commissioned; externally peer reviewed.

Data availability statement All data relevant to the study are included in the article or uploaded as online supplementary information. Relevant data have been uploaded as supplementary material. Any further doubts will be clarified if needed.

Open access This is an open access article distributed in accordance with the Creative Commons Attribution Non Commercial (CC BY-NC 4.0) license, which permits others to distribute, remix, adapt, build upon this work non-commercially, and license their derivative works on different terms, provided the original work is properly cited, appropriate credit is given, any changes made indicated, and the use is non-commercial. See: http://creativecommons.org/licenses/by-nc/4.0/.

ORCID iD

Sunil Kumar Nayak http://orcid.org/0000-0003-2659-1286 


\section{REFERENCES}

1 Glick PL, Boulanger SC. Inguinal Hernias and Hydroceles. In: Goran AG, Adzick NS, Caldamone AA, eds. Pediatric surgery. 7th edn. Philadelphia: Elsevier, 2012: 985-1001.

2 Chinnaswamy P, Malladi V, Jani KV, et al. Laparoscopic inguinal hernia repair in children. JSLS 2005;9:393-820.

3 El-Gohary MA. Laparoscopic ligation of inguinal hernia in girls. Pediatr Endosurg Innovative Techniques 1997;1:185-8.

4 Schier F. Laparoscopic herniorrhaphy in girls. J Pediatr Surg 1998;33:1495-7.

5 Montupet P, Esposito C. Laparoscopic treatment of congenital inguinal hernia in children. J Pediatr Surg 1999;34:420-3.

6 Gorsler CM, Schier F. Laparoscopic herniorrhaphy in children. Surg Endosc 2003;17:571-3.

7 Becmeur F, Philippe P, Lemandat-Schultz A, et al. A continuous series of 96 laparoscopic inguinal hernia repairs in children by a new technique. Surg Endosc 2004:18:1738-41.

8 Marte A, Sabatino MD, Borrelli M, et al. Decreased recurrence rate in the laparoscopic herniorraphy in children: comparison between two techniques. J Laparoendosc Adv Surg Tech A 2009;19:259-62.

9 Yip KF, Tam PKH, Li MKW. Laparoscopic flip-flap hernioplasty: an innovative technique for pediatric hernia surgery. Surg Endosc 2004;18:1126-9.

10 Li S, Li M, Wong KKY, et al. Laparoscopically assisted simple suturing obliteration (LASSO) of the internal ring using an epidural needle: a handy single-port laparoscopic herniorrhaphy in children. J Pediatr Surg 2014;49:1818-20.

11 Harrison MR, Lee H, Albanese CT, et al. Subcutaneous endoscopically assisted ligation (SEAL) of the internal ring for repair of inguinal hernias in children: a novel technique. J Pediatr Surg 2005;40:1177-80.

12 Esposito C, Escolino M, Turrà F, et al. Current concepts in the management of inguinal hernia and hydrocele in pediatric patients in laparoscopic era. Semin Pediatr Surg 2016;25:232-40.

13 Grosfeld JL, Minnick K, Shedd F, et al. Inguinal hernia in children: factors affecting recurrence in 62 cases. J Pediatr Surg 1991;26:283-7.

14 Shehata S, Shehata S, Wella HL, et al. Pediatric inguinal hernias, are they all the same? A proposed pediatric hernia classification and tailored treatment. Hernia 2018;22:941-6.
15 Lee SR, Park PJ. Adding iliopubic tract repair to high ligation reduces recurrence risk in pediatric laparoscopic transabdominal inguinal hernia repair. Surg Endosc 2020. doi:10.1007/s00464-02007382-1. [Epub ahead of print: 14 Jan 2020].

16 Schier F. Direct inguinal hernias in children: laparoscopic aspects. Pediatr Surg Int 2000;16:562-4.

17 Esposito C, Montupet P. Laparoscopic treatment of recurrent inguinal hernia in children. Pediatr Surg Int 1998;14:182-4.

18 Kantor N, Travis N, Wayne C, et al. Laparoscopic versus open inguinal hernia repair in children: which is the true gold-standard? A systematic review and meta-analysis. Pediatr Surg Int 2019;35:1013-26.

19 Dreuning K, Maat S, Twisk J, et al. Laparoscopic versus open pediatric inguinal hernia repair: state-of-the-art comparison and future perspectives from a meta-analysis. Surg Endosc 2019;33:3177-91.

20 Chen KC, Chu CC, Chou TY, et al. Ultrasonography for inguinal hernias in boys. J Pediatr Surg 1998;33:1784-7.

21 Erez I, Rathause V, Vacian I, et al. Preoperative ultrasound and intraoperative findings of inguinal hernias in children: a prospective study of 642 children. J Pediatr Surg 2002;37:865-8.

22 Ozgediz D, Roayaie K, Lee H, et al. Subcutaneous endoscopically assisted ligation (SEAL) of the internal ring for repair of inguinal hernias in children: report of a new technique and early results. Surg Endosc 2007;21:1327-31.

23 Wulkan ML, Wiener ES, VanBalen N, et al. Laparoscopy through the open ipsilateral sac to evaluate presence of contralateral hernia. $J$ Pediatr Surg 1996;31:1174-7. discussion 1176-7.

24 Zamakhshardy M, Ein A, Ein SH, et al. Predictors of metachronous inguinal hernias in children. Pediatr Surg Int 2009;25:69-71.

25 Ikeda H, Suzuki N, Takahashi A, et al. Risk of contralateral manifestation in children with unilateral inguinal hernia: should hernia in children be treated contralaterally? J Pediatr Surg 2000;35:1746-8.

26 Tackett LD, Breuer CK, Luks FI, et al. Incidence of contralateral inguinal hernia: a prospective analysis. J Pediatr Surg 1999;34:684-8. 